\title{
Supra-threshold stochastic resonance in a population of stochastic Hogkin-Huxley neuron models with random ion channel gating
}

Hiroyuki Mino

From Nineteenth Annual Computational Neuroscience Meeting: CNS*2010

San Antonio, TX, USA. 24-30 July 2010

Supra-threshold stochastic resonance (SSR) refers to a phenomenon what an optimally added noise can enhance information transmission when a supra-threshold signal is driven into an array of non-linear systems with threshold [1]. The noise in neurons has been considered to come up from not only randomness of synaptic vesicle secretions (extrinsic fluctuations) but also stochasticity of ion channel gating (intrinsic fluctuations). However, it is still unclear whether and how those fluctuations help enhance information transmission in the case of supra-threshold input signals. The objective of this presentation was to see how randomness of ion channel gating could affect spike firing times and mutual information, and if SSR could be observed or not through computer simulations.

\section{Methods and results}

A supra-threshold filtered Poisson process with an intensity of $10\left[\mathrm{~s}^{-1}\right]$ was applied into an array of 50 stochastic Hodgkin-Huxley (HH) neuron models possessing stochastic sodium and potassium channels with a patch area of $100,200, \ldots$, and $700\left[\mathrm{um}^{2}\right]$. The stochastic ion channel gating was implemented by the channel-number tracking algorithm [2]. Each output spike train of neuron models was gathered and moving-averaged for calculating the rate of spike trains. Ten kinds of input realizations were applied repeatedly ten times to the array in order to estimate the total and noise entropies of the spike firing rate for calculating mutual information. Figures 1 and 2.

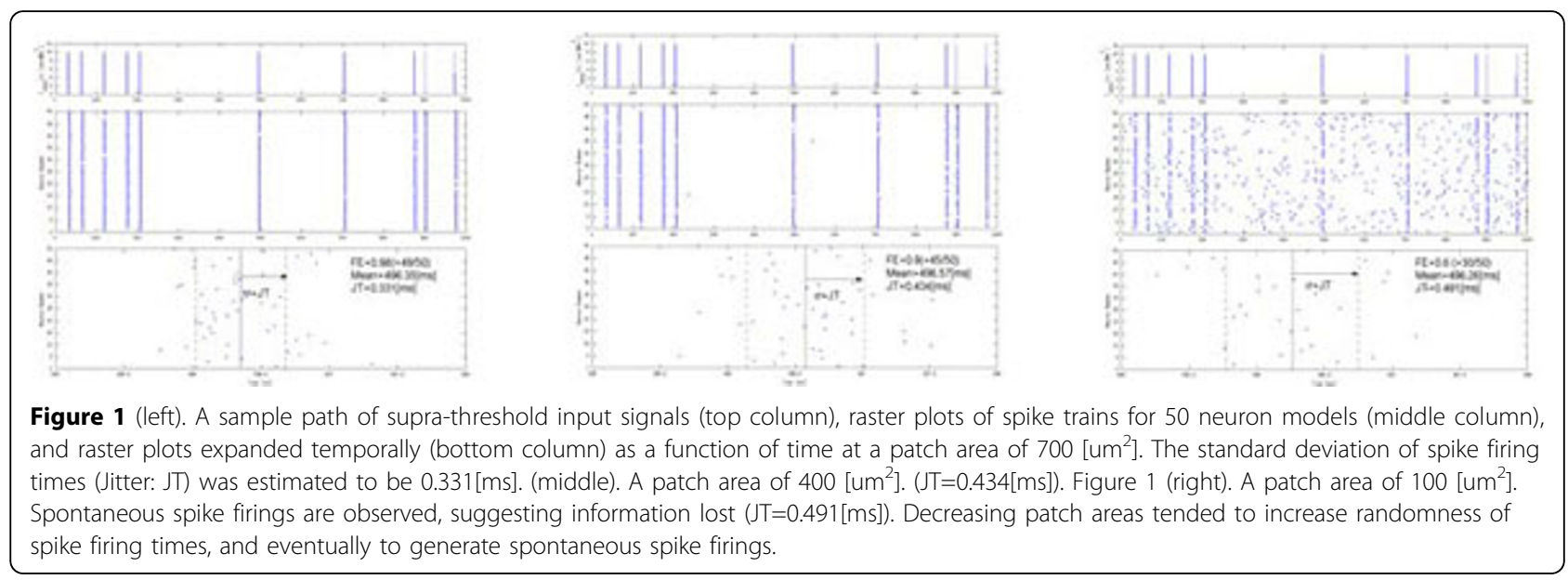

Correspondence: mino@ieee.org

Department of Electrical and Computer Engineering, Kanto Gakuin

University, Yokohama 236-8501, Japan 


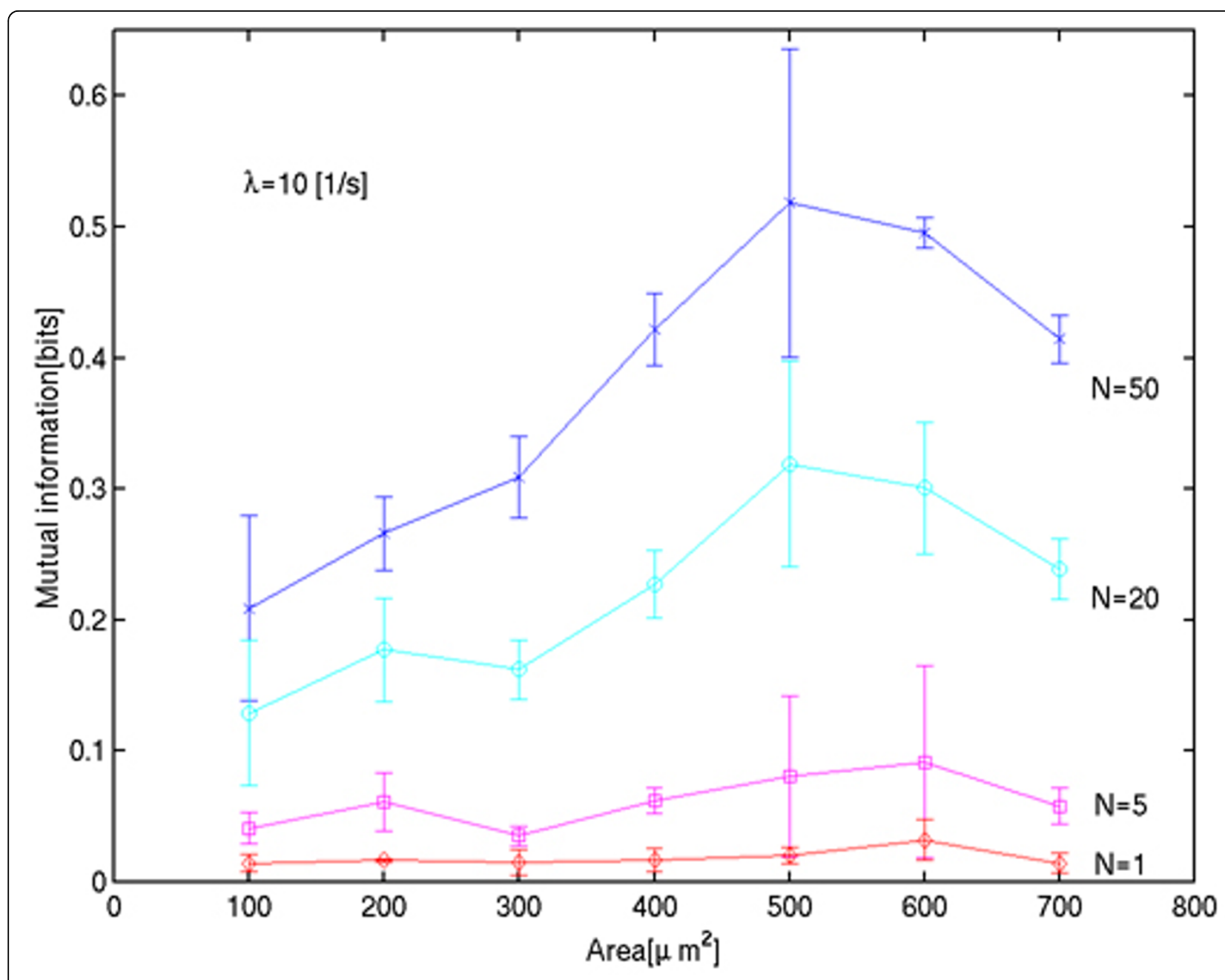

Figure 2 Mutual information as a function of patch area for the number of neuron models ( $\mathrm{N}$ ) being set at 1, 5, 20, and 50. SSR was observed remarkably for $\mathrm{N}$ greater than 20 , while it did not so for $\mathrm{N}$ smaller than 5 .

\section{Conclusion}

It follows that the mutual information was maximized at an optimal patch size in an array of stochastic $\mathrm{HH}$ neuron models, and therefore that SSR was observed in the presence of intrinsic fluctuations. This phenomenon may be aptly called "intrinsic" SSR (ISSR). ISSR could play a key role in processing excessive input signals into sensory nervous systems.

Published: 20 July 2010

\section{References}

1. Stocks NG: Suprathreshold stochastic resonance in multilevel threshold systems. Phys. Rev. Lett 2000, 84:2310-2313.

2. Mino $\mathrm{H}$, et al: Comparison of algorithms for the simulation of action potentials with stochastic sodium channels. Ann. Biomed. Eng. 2002, 30:578-587.
doi:10.1186/1471-2202-11-S1-P177

Cite this article as: Mino: Supra-threshold stochastic resonance in a population of stochastic Hogkin-Huxley neuron models with random ion channel gating. BMC Neuroscience 2010 11(Suppl 1):P177.

Submit your next manuscript to BioMed Central and take full advantage of:

- Convenient online submission

- Thorough peer review

- No space constraints or color figure charges

- Immediate publication on acceptance

- Inclusion in PubMed, CAS, Scopus and Google Scholar

- Research which is freely available for redistribution 